\title{
HUBUNGAN ANTARA MEROKOK DENGAN HIPERTENSI DI PUSKESMAS KAWANGKOAN
}

\author{
Irene Megawati Umbas \\ Josef Tuda \\ Muhamad Numansyah \\ Program Studi Ilmu Keperawatan Kedokteran \\ Universitas Sam Ratulangi \\ Email: ireineumbas7@gmail.com
}

\begin{abstract}
Abstrack: A person can be said to be a smoker if he has smoked at least 100 cigarettes. Someone who smoked cigarettes more than one pack of cigarettes per day to 2 times more susceptible to hypertension than those who do not smoke. Danger hypertension triggers damage to organs including: kidney, brain, heart, eyes, cause vascular resistance and stroke. The purpose of this study is to know relationship between between smoking and hypertension at Public Health Center Kawangkoan. The method of this study uses cross sectional study design. The sample of this study amounted to 74 students with total sampling method. The results of this study were obtained from 74 respondents studied the majority of smokers were hypertensive, first degree 19 respondents, hypertension high normal 13 respondents, hypertension degree II 11 respondents. Heavy smoker degree II hypertension 18 respondents, first degree hypertension 9 respondents, hypertension normal height of 4 respondents, using the chi-square test at the level meaning 95\%, it was found that the value of p-value was 0.016 smaller than the significant value 0.05. The conclusion of this study is that there is a relationship between Smoking and Hypertension at Public Health Center Kawangkoan.
\end{abstract}

Keywords: Smoking, Hypertension

Abstrak: Seseorang dikatakan perokok jika telah menghisap minimal 100 batang rokok. Seseorang menghisap rokok lebih dari satu bungkus rokok per hari menjadi 2 kali lebih rentan terhadap hipertensi dari pada mereka yang tidak merokok. Bahaya hipertensi memicu rusaknya organ tubuh diantaranya: ginjal, otak, jantung, mata, menyebabkan resistensi pembuluh darah dan stroke. Tujuan: Studi ini untuk mengetahui hubungan antara Merokok dengan Hipertensi di Puskesmas Kawangkoan. Metode: Studi ini menggunakan desain penelitian cross-sectional. Sampel: Studi ini berjumlah 74 responden dengan pengambilan sampel Total-Sampling. Hasil: Dari penelitian ini, didapatkan dari 74 responden yang diteliti sebagian besar perokok sedang hipertensi derajat I 19 responden, hipertensi normal tinggi 13 reponden, hipertensi derajat II 11 responden. Perokok berat hipertensi derajat II 18 responden, hipertensi derajat I 9 responden, hipertensi normal tinggi 4 responden, dengan menggunakan uji chi-square pada tingkat kemaknaan 95\%, didapat bahwa nilai p-value adalah 0,016 lebih kecil dari nilai signifikan 0,05. Kesimpulan: Dari penelitian ini bahwa terdapat hubungan antara Merokok dengan Hipertensi di Puskesmas Kawangkoan.

Kata Kunci: Merokok, Hipertensi 


\section{PENDAHULUAN}

Hipertensi merupakan salah satu penyebab kematian dini pada masyarakat di dunia dan semakin lama, permasalahan tersebut semakin meningkat. WHO telah memperkirakan pada tahun 2025 nanti, 1,5 milyar orang di dunia akan menderita hipertensi tiap tahunnya. Penyakit hipertensi merupakan the silent disease karena orang tidak mengetahui dirinya terkena hipertensi sebelum memeriksakan tekanan darahnya (Rudianto, 2013). Tingginya angka kejadian hipertensi di dunia, dipengaruhi oleh dua jenis faktor, yaitu yang tidak bisa diubah seperti umur, jenis kelamin, dan ras. Faktor yang bisa diubah diantaranya obesitas, konsumsi alkohol, kurang olahraga, konsumsi garam yang berlebihan, dan kebiasaan merokok (Setyanda, 2015). Salah satu faktor risiko hipertensi adalah kebiasaan merokok. Faktor risiko hipertensi lainnya antara lain umur, jenis kelamin, riwayat keluarga, dan genetic (faktor resiko yang tidak dapat diubah/dikontrol), serta kebiasaan mengonsumsi garam, konsumsi lemak jenuh, penggunaan jelantah, kebiasaan konsumsi minuman beralkohol, obesitas, kurang estrogen/kontrasepsi pil KB (Kemenkes RI, 2014).

Merokok dan hipertensi adalah dua faktor risiko yang terpenting dalam penyakit aterosklerosis, penyakit jantung koroner, infark miokard akut, dan kematian mendadak. Merokok telah menyebabkan 5,4 juta orang meninggal setiap tahun (Gumus et al, 2013). Pada penelitian yang telah banyak dilakukan, dijelaskan bahwa efek akut yang disebabkan oleh merokok antara lain meningkatkan denyut jantung dan tekanan darah dengan adanya peningkatan kadar hormon epinefrin dan norepinefrin karena aktivasi sistem saraf simpatis. Banyak penelitian juga mengatakan bahwa efek jangka panjang dari merokok adalah peningkatan tekanan darah karena adanya peningkatan zat inflamasi, disfungsi endotel, pembentukan plak, dan kerusakan vaskular (Gumus et al, 2013). Perokok dapat diklasifikasikan berdasarkan banyak rokok yang dihisap perhari. Bustan membaginya ke dalam 3 kelompok, yang dikatakan perokok ringan adalah perokok yang menghisap 1 - 10 batang rokok sehari, perokok sedang, 11 - 20 batang sehari, dan perokok berat lebih dari 20 batang rokok sehari. Merokok dapat menyebabkan hipertensi akibat zat-zat kimia yang terkandung dalam tembakau terutama nikotin yang dapat merangsang saraf simpatis sehingga memicu kerja jantung lebih cepat sehingga peredaran darah mengalir lebih cepat dan terjadi penyempitan pembuluh darah, serta peran karbon monoksida yang dapat menggantikan oksigen dalam darah dan memaksa jantung memenuhi kebutuhan oksigen tubuh (Sukmana, 2009). Diperkirakan terdapat 1,26 miliar perokok aktif yang ada di dunia. Data epidemi tembakau di dunia menunjukkan tembakau membunuh lebih dari 5 (lima) juta orang setiap tahunnya. Jika hal tersebut terus berlanjut maka diproyeksikan akan terjadi 10 (sepuluh) juta kematian pada tahun 2020, dengan $70 \%$ kematian terjadi di negara sedang berkembang. Dari segi jumlah perokok Indonesia merupakan Negara dengan jumlah penduduk terbesar ke-4 setelah China (WHO 2012). Indonesia menduduki peringkat ke-3 negara perokok terbesar di dunia. Hal tersebut menunjukkan tingginya jumlah perokok di Indonesia yang mencapai 29,2\% dari jumlah keseluruhan penduduk. Jumlah ini terus meningkat dari tahun ke tahun dengan berkembangnya perusahaan rokok di Indonesia (WHO, 2008).

Prevalensi perokok di Indonesia pada tahun 2013 sebesar 29,3\%, dengan jumlah perokok pada laki-laki sebanyak $47,5 \%$ dan perempuan 1,1\%. Hasil Global Adult Tobacco Survey (GATS) tahun 2011 menunjukkan, Indonesia menduduki posisi pertama dengan prevalensi perokok aktif bila dibandingkan dengan negara-negara lain yang melaksanakan GATS, yaitu $67,4 \%$ pada lakilaki dan 2,7\% pada wanita. Menurut laporan Riskesdas tahun 2010, persentase perokok di pedesaan lebih tinggi dibandingkan persentase perokok di perkotaan. Dari 86.869 responden di pedesaan, sebanyak $37,4 \%$ merupakan perokok aktif, sedangkan di perkotaan sebanyak $32,4 \%$ responden merupakan perokok aktif dari 91.057 responden. Di Indonesia berdasarkan 
pengukuran pada usia > 18 tahun sebesar 25,8\% (Rikesdas 2013). Dilihat dari data STP berbasis puskesmas Dinas Kesehatan Provinsi Sulut terdapat banyak penderita hipertensi sehingga hipertensi masuk dalam 10 penyakit menonjol di Sulawesi utara yaitu pada tahun 2014 dengan 33.093 kasus, tahun 2015 dengan 24.965 kasus, dan tahun 2016 dengan 16.718 kasus (Dinkes Prov.Sulut, 2016). Provinsi Sulawesi Utara pada tahun 2016 jumlah kasus hipertensi berada pada peringkat kedua di sepuluh penyakit menonjol terdapat 32.742 kasus hipertensi (Dinkes Provinsi Sulut, 2016). Dan untuk Kabupaten Minahasa pada tahun 2017 penderita hipertensi mencapai 18.536 kasus hipertensi (Dinkes Kabupaten Minahasa, 2017). Berdasarkan survei pendahuluan yang dilakukan di Puskesmas Kawangkoan pada tanggal 26 Januari 2019, diperoleh data hipertensi sebanyak 819 pada tahun 2017, dan ditahun 2018 mengalami kenaikan sebanyak 936, setelah dilakukan survey di wilayah kerja Puskesmas Kawangkoan dengan mengobservasi banyaknya masyarakat yang masih merokok baik laki-laki maupun perempuan, dan masih banyak yang merokok di lingkungan Puskesmas Kawangkoan maupun diluar lingkungan Puskesmas Kawangkoan. Berdasarkan wawancara pada beberapa orang yang merokok laki-laki maupun perempuan disalah satu kelurahan di wilayah kerja Puskesas Kawangkoan, mereka mengatakan bahwa dalam sehari saja bisa mengabiskan rokok kurang lebih 20 batang/hari.

\section{METODE PENELITIAN}

Desain penelitian yang digunakan adalah Cross-Sectional yang menghubungkan antara dua variabel, yaitu variabel bebas (merokok) dengan variabel terikat (hipertensi), dan menggunakan pendekatan Cross Sectional (Setiadi, 2013). Penelitian telah dilaksanakan di Puskesmas Kawangkoan. Penelitian ini telah dilaksanakan pada bulan Februari - Maret tahun 2019. Seluruh penderita hipertensi dan merokok di Puskesmas Kawangkoan pada dua bulan terakhir pada tahun 2018 yang berjumlah 215. Pada penelitian ini teknik sampling yang digunakan adalah total sampling. Sampel pada penelitian ini adalah seluruah responden yang merokok dan hipertensi di Puskesmas Kawangkoan. Dalam penelitian merokok dengan hipertensi, kriteria sampel meliputi kriteria inklusi dan kriteria ekslusi. Sampel yang memenuhi kriteria didapatkan berjumlah 74 sampel. Penelitian ini menggunakan instrument dengan melakukan wawancara secara langsung kepada responden dan menggunakan data sekunder dari Puseksamas Kawangkoan data yang di dapatkan dari rekam medik untuk mengetahui tekanan darah dari responden. Pengolahan data yang diperoleh dari penelitian ini dan diolah secara manual selanjutnya dilakukan analisis menggunakan uji statistik. Setelah itu diolah menggunakan system komputerisasi, tahap-tahap tersebut yaitu editing, coding, processing, dan cleaning.

Analisis univariat pada penelitian ini akan menghasilkan distribusi frekuensi yang memberi gambaran mengenai jumlah dan presentase. Analisis univariat dilakukan untuk menganalisis karateristik responden, variabel merokok dan variabel hipertensi. Analisis bivariat merupakan analisis hasil dari variabel independent diduga memiliki hubungan dengan variabel dependen. Analisis yang digunakan adalah hasil tabulasi silang. Untuk menguji hipotesa dilakukan analisis statistik dengan menggunakan uji statistic chi square pada tingkat kemaknaan 95\% (p-Value < 0,05). Hasil uji statistik di peroleh nilai $\mathrm{p}<\alpha=0,05$ ), maka dengan demikian dapat dikatakan bahwa Ha diterima yaitu terdapat hubungan antara merokok dengan hipertensi di Puskesmas Kawangkoan. Dalam melakukan penelitian, peneliti memperhatikan masalah-masalah etika penelitian yang meliputi: informed consent, anonimity, confidentialy. 
HASIL dan PEMBAHASAN

\section{Analisa Univariat}

Tabel 1. Distributor responden berdasarkan perokok.

\begin{tabular}{ccc}
\hline Perokok & n & \% \\
\hline Sedang & 43 & 58.1 \\
Berat & 31 & 41.9 \\
\hline Total & $\mathbf{7 4}$ & $\mathbf{1 0 0 \%}$ \\
\hline
\end{tabular}

Sumber: Data Primer 2019.

Berdasarkan hasil penelitian yang dilakukan di Puskesmas Kawangkoan menunjukan bahwa dari 74 reponden yang mendapatkan perokok yang paling banyak adalah perokok sedang sebanyak $58.1 \%$. Penelitian ini sejalan dengan Handayani, 2015 tentang hubungan perilaku merokok dengan angka kejadian hipertensi di desa Trosobo Kecamatan Sambi Kabupaten Boyolali dengan sampel 68 responden didapatkan hasil mayoritas yang berperilaku merokok sedang sebanyak 37 responden (54.44\%). Penelitian ini tidak didukung oleh Retnaningsih D. 2017 tentang perilaku merokok dengan kejadian hipertensi pada lansia menunjukan hasil penelitian dari 50 responden menunjukkan bahwa sebagian besar lansia laki-laki memiliki perilaku merokok dalam kategori berat dengan jumlah 11 orang $(22,0 \%)$, yaitu perilaku merokok yang mengkonsumsi rokok 11- 21 batang dengan selang waktu 31-60 menit dari bangun tidur. Menurut Aula (2010) jumlah konsumsi rokok per hari dapat digunakan sebagai indikator tingkat merokok seseorang. Dalam penelitian ini konsumsi rokok dikategorikan menjadi 3 yaitu mengkonsumsi rokok 11- 21 batang dengan selang waktu 3160 menit dari bangun tidur (perokok ringan), mengkonsumsi merokok sekitar 21-31 batang sehari dengan selang waktu sejak bangun tidur berkisar 6-30 menit (perokok sedang, dan mengkonsumsi rokok lebih dari 31 batang perhari dengan selang waktu merokok 5 menit setelah bangun pagi (perokok berat).

Perilaku merokok pada orang dewasa dan remaja umumnya semakin meningkat sesuai dengan tahap perkembangan yang ditandai dengan meningkatnya frekuensi dan intensitas merokok, dan sering mengakibatkan mereka mengalami ketergantungan nikotin. Nikotin dapat menimbulkan ketagihan, baik pada perokok aktif maupun perokok pasif. Nikotin merupakan alkaloid yang bersifat stimulan (Mukuan, 2012). Perilaku merokok adalah menghisap asap tembakau yang telah menjadi cerutu kemudian disulut api. Menurutnya ada dua tipe merokok. Pertama adalah menghisap rokok secara langsung yang disebut perokok aktif, dan yang kedua mereka yag secara tidak langsung menghisap rokok. Namun turut menghisap asap rokok disebut perokok pasif. Bermacam-macam perilaku yang dilakukan manusia dalam menanggapi stimulus yang diterimanya, salah satu bentuk perilaku manusia yang dapat diamati adalah perilaku merokok (Sukmana, 2008). Orang dengan kebiasaan merokok memiliki resiko terserang hipertensi dibandingkan orang yang tidak merokok, hal ini menunjukkan bahwa kebiasaan merokok merupakan salah satu pencetus terjadinya penyakit hipertensi. Hal ini dikarenakan adanya faktor-faktor lain yang mempengaruhi seperti faktor lingkungan, dalam hal ini masyarakat Kawangkoan merupakan masyarakat yang sering dikunjungi oleh petugas petugas kesehatan, termasuk petugas kesehatan dari Puskesmas Kawangkoan sehingga pengetahuan mengenai bahaya rokok dapat diketahui dengan baik.

Tabel 2. Distribusi responden berdasarkan hipertensi.

\begin{tabular}{ccc}
\hline Hipertensi & n & \% \\
\hline Normal Tinggi & 17 & 23.0 \\
Hipertensi Derajat I & 28 & 37.8 \\
Hipertensi Derajat II & 29 & 39.2 \\
\hline Total & $\mathbf{7 4}$ & $\mathbf{1 0 0 \%}$ \\
\hline
\end{tabular}

Sumber: Data Primer 2019.

Berdasarkan hasil penelitian yang dilakukan di Puskesmas Kawangkoan menunjukan bahwa dari 74 reponden responden paling banyak adalah responden Hipertensi Derajat II sebanyak 32.2\% (29 orang). Penelitian ini sejalan dengan Sriani 2017 tentang hubungan antara perilaku merokok dan kebiasaan olahraga dengan 
kejadian hipertensi pada laki-laki usia 18-44 tahun diketahui bahwa responden yang mengalami hipertensi lebih banyak dibandingkan dengan yang tidak hipertensi, yaitu sebanyak $59(54,13 \%)$ orang. Penelitian juga dilakukan oleh Kurniawan, 2017 tentang hubungan perilaku merokok dengan kejadian hipertensi di Puskesmas Pajangan Bantul dengan hasil dapat diketahui bahwa karakteristik responden berdasarkan kejadian hipertensi pada pasien hipertensi di Puskesmas Pajangan Bantul, sebagian besar adalah responden termasuk kategori Hipertensi Grade I yaitu sebanyak 33 responden $(84,6 \%)$.

Faktor risiko yang memicu terjadinya hipertensi dibagi menjadi dua yaitu faktor yang tidak dapat dikontrol dan faktor yang dapat dikontrol. Faktor yang tidak dapat dikontrol meliputi usia, jenis kelamin, dan keturunan (genetik). Faktor yang dapat dikontrol meliputi kegemukan (obesitas), dislipidemia, stress, konsumsi alkohol berlebih, konsumsi garam berlebih, aktivitas fisik, diet yang tidak seimbang dan merokok (Sudarmoko, 2015). Hipertensi pada penelitian ini banyak ditemukan pada kelompok hipertensi Grade II, hal ini dikarenakan kelompok umur dua puluh tahun yang terbanyak dalam penelitian ini, kelemahan yang ditemukan pada penelitian ini yakni kesibukan responden sebagian besar adalah berhubungan dengan fisik, sehingga kesadaran setiap mahasiswa untuk melakukan olahraga dengan waktu yang dikhususkan menjadi berkurang. Mahasiswa beranggapan bahwa aktivitas mereka sudah termasuk olahraga, sehingga responden yang tidak beraktivitas fisik atau aktivitas fisiknya tidak ideal lebih banyak dibandingkan yang teratur berolahraga.

Penyakit Hipertensi dapat dipengaruhi oleh cara dan kebiasaan hidup seseorang, salah satunya adalah kebiasaan merokok. Merokok merupakan bagian hidup masyarakat dan salah satu kebiasaan yang sering ditemui dalam kehidupan sehari-hari. Orang merokok bisa pada siapa saja seperti laki-laki, perempuan, remaja, kaya, miskin dan tidak ada terkecuali. Merokok merupakan bagian hidup masyarakat. Dimana dari segi kesehatan, tidak ada satu orang pun yang menyetujui atau melihat manfaat yang dikandungnya dan tidak mudah menurunkan dan menghilangkannya, karena itu gaya hidup ini menarik sebagai suatu masalah kesehatan dan dianggap sebagai faktor risiko terkena penykit hipertensi (Bustan, 2007).

\section{Analisis Bivariat}

Tabel 3. Hubungan antara merokok dengan hipertensi di Puskesmas Kawangkoan

\begin{tabular}{|c|c|c|c|c|c|c|c|c|c|}
\hline \multirow{3}{*}{ Merokok } & \multicolumn{8}{|c|}{ Hipertensi } & \multirow{3}{*}{$\begin{array}{c}p- \\
\text { value }\end{array}$} \\
\hline & \multicolumn{2}{|c|}{$\begin{array}{c}\text { Normal } \\
\text { Tinggi }\end{array}$} & \multicolumn{2}{|c|}{ Hpt I } & \multicolumn{2}{|c|}{ Hpt II } & \multicolumn{2}{|c|}{ Total } & \\
\hline & $\mathrm{n}$ & $\%$ & $\mathrm{n}$ & $\%$ & $\mathrm{n}$ & $\%$ & $\mathrm{n}$ & $\%$ & \\
\hline Sedang & 13 & 30.2 & 19 & 44.2 & 11 & 25.6 & 43 & 100 & \\
\hline Berat & 4 & 12.9 & 9 & 29 & 18 & 58.1 & 31 & 100 & 0.016 \\
\hline Total & 17 & 23 & 28 & 37.8 & 29 & 39.2 & 74 & 100 & \\
\hline
\end{tabular}

Sumber: Data Primer 2019.

Berdasarkan hasil penelitian dari 74 responden menunjukan bahwa dari 74 sampel didapatkan perokok sedang hipertensi derajat I sebanyak 19 responden, hipertensi normal tinggi 13 reponden, hipertensi derajat II sebanyak 11 responden. Perokok berat hipertensi derajat II sebanyak 18 responden, hipertensi derajat I sebanyak 9 responden, hipertensi normal tinggi sebanyak 4 responden. Hasil analisa dengan uji hipotesis dari merokok dengan hipertensi menggunakan uji chi-square dengan tingkat kepercayaan 95\% ( $\mathrm{P}$ value < 0,05), menunjukan adanya hubungan yang signifikan antara merokok dengan hipertensi dimana $P$ Value $=0,016$ lebih kecil dari $\mathrm{P}$ value $<0,05$. Penelitian yang sama oleh Paat (2014) Penelitian dilakukan di Desa Motoling Dua Kecamatan Motoling Kabupaten Minahasa Selatan diperoleh responden yang merokok dengan riwayat hipertensi berjumlah 71 responden (53.0\%), dengan hasil uji statistik Chi Square membuktikan bahwa ada hubungan antara status merokok dengan kejadian hipertensi pada laki-laki usia 40-65 tahun dengan nilai $p=0,001$. Atau $\leq 0.05$. Penelitian ini juga didukung oleh Yashinta, 2015 tentang hubungan merokok dengan kejadian hipertensi pada laki - laki usia 35-65 tahun di Kota Padang Hasil uji chi-square didapatkan 
adanya hubungan bermakna antara jenis rokok dengan kejadian hipertensi $(\mathrm{p}=0,017)$. Merokok merupakan salah satu faktor yang bisa diubah, hubungan rokok dengan hipertensi yaitu nikotin yang menyebabkan peningkatan tekanan darah karena nikotin didalam rokok diserap pembuluh darah kecil dalam paru-paru sehingga diedarkan oleh pembuluh darah ke otak, otak akan beraksi terhadap nikotin dengan memberi sinyal pada kelenjar adrenal sehingga bisa melepas efinefrin (Adrenalin). Hormon yang kuat ini akan menyempitkan pembuluh darah sehingga jantung dipaksa bekerja lebih berat dan menyebabkan tekanan darah lebih tinggi. Karbon monoksida dalam asap rokok menggantikan oksigen dalam darah. Hal ini mengakibatkan tekanan darah karena jantung dipaksa memompa untuk memasukan oksigen yang cukup ke dalam organ dan jaringan tubuh (Samiadi, 2016). Zat-zat kimia beracun dalam rokok dapat mengakibatkan tekanan darah tinggi atau hipertensi. Salah satu zat beracun tersebut yaitu nikotin, dimana nikotin dapat meningkatkan adrenalin yang membuat jantung berdebar lebih cepat dan bekerja lebih keras, frekuensi denyut jantung meningkat dan kontraksi jantung meningkat sehingga menimbulkan tekanan darah meningkat (Aula, 2010).

Perbedaan tingkat hipertensi yang terjadi karena perbedaan jumlah konsumsi rokok, pada dasarnya merokok berpengaruh terhadap kejadian hipertensi. Zat-zat kimia beracun seperti nikotin dan karbon monoksida yang dihisap melalui rokok yang masuk kedalam aliran darah dapat merusak lapisan endotel pembuluh darah arteri, mengakibatkan proses aterosklerosis dan tekanan darah tinggi. Pada studi autopsi dibuktikan kaitan erat antara kebiasaan merokok dengan adanyaa terosklerosis pada seluruh pembuluh darah. Merokok pada penderita tekanan darah tinggi semakin meningkatkan resiko kerusakan pada pembuluh darah arteri (Priyoto, 2015). Berdasarkan hasil penelitan peneliti berasumsi bahwa responden di Puskesmas Kawangkoan yang menjadi sampel penelitian saat ini dibuktikan dengan hasil wawancara sebelumnya kepada responden bahwa banyak responden yang hipertensi derajat II karena mereka merokok rata-rata $\geq 16$ batang/1 bungkus per hari, berdasarkan wawancara rokok yang di hisap adalah rokok filter/rokok yang pada pangkalnya terdapat gabus. Dalam penelitian ini peneliti mendapat responden beberapa orang perempuan namun yang lebih banyak laki-laki. Menurut pekerjaan dan pendapatan mereka rata-rata diwilayah kerja Pukesmas Kawangkoan memiliki pekerjaan dan pendapatan yang cukup. Faktor gaya hidup masyarakat di Kawangkoan juga mulai menunjukkan perubahan seiring dengan perkembangan teknologi. Masyarakat disana mulai mengurangi beberapa gaya hidup yang dapat menjadi faktor pencetus terjadinya hipertensi, seperti mengkonsumsi lemak berlebih dan kurang berolahraga. Meskipun jumlah penderita penyakit hipertensi yang ditemukan lebih sedikit dibandingkan dengan yang tidak menderita penyakit hipertensi, namun hal ini tidak dapat diabaikan, diperlukan adanya penanggulangan yang baik dalam mengurangi kejadian penyakit hipertensi di Puskesmas setempat.

\section{SIMPULAN}

Berdasarkan hasil penelitian yang dilakukan di Puskesmas Kawangkoan, sebagian besar responden mendapatkan perokok sedang dan sebagian besar responden mendapatkan Hipertensi derajat II. Terdapat hubungan antara merokok dengan hipertensi di Puskesmas Kawangkoan.

\section{DAFTAR PUSTAKA}

Aula, L. Ellizabet (2010). Stop Merokok. Jogjakarta : Gara Ilmu.

Bustan, M.N. 2007. Epidemiologi Penyakit Tidak Menular. Jakarta: Rineka Cipta

Dinas Kesehatan Provinsi Sulawesi Utara. 2016. Buku Saku Profil Kesehatan Provinsi Sulawesi Utara tahun 2016. Manado

Dinas Kesehatan Kabupaten Minahasa. 2017. Profil Kesehatan Kab. Minahasa. Minahasa 
GATS. 2011. Global Adults Tobacco Survey Indonesia Report 2011. New Delhi: WHO Regional Office For South-East Asia.

Gumus, A., Cinarka, H., Baydur, S., Kayhan, S., Giakoup, D., \& Sahin, U. (2014). The relationship between cigarette smoking and obesity. Journal of Experimental and Clinical Medicine, 30(4), 311-315. https://doi.org/10.5835/jecm.omu.30.04. $\underline{006}$

Handayani, W. (2015). Hubungan Perilaku Merokok Dengan Angka Kejadian Hipertensi Di Desa Trosobo Kecamatan Sambi Kabupaten Boyolali. Program Studi Kesehatan Masyarakat, Fakultas Kedokteran, Universitas Lambung Mangkurat

Kemenkes RI. Profil Kesehatan Indonesia tahun 2014. Jakarta : Kemenkes RI; 2014.

Kurniawan. (2017). Hubungan Perilaku Merokok dengan kejadian Hipertensi di Puskesmas Pajangan Bantul, 1, 18-23.

Mukuan, S. E. (2012). Hubungan Antara Pengetahuan dan Sikap Tentang Bahaya Merokok bagi Kesehatan dengan Tindakan Merokok Pelajar SMK Kristen Kawangkoan. Jurnal Euginia Vol. 1 No. 1,

Paat, I. 2014. Hubungan Antara Konsumsi Alkohol Dan Status Merokok Dengan Kejadian Hipertensi Pada Laki-laki Usia 40-65 Tahun Di Desa Motoling 2 Kecamatan Motoling Kabupaten Minahasa Selatan.Manado: Universitas Sam Ratulangi.

Priyoto. (2015). Teori Sikap Dan Perilaku Dalam Kesehatan. Yogyakarta:

Retnaningsih D. (2017). Perilaku Merokok Dengan Kejadian Hipertensi Pada Lansia. STIKES Wisya Husada Semarang.
Riset Kesehatan Dasar (Riskesdas 2010). Kementrian Kesehatan Republik Indonesia, Jakarta.

Riset Kesehatan Dasar (Riskesdas 2013). Kementrian Kesehatan Republik Indonesia, Jakarta.

Rudianto, Budi F. 2013. Menaklukan Hipertensi dan Diabetes. Yogyakarta: Sakkhasukma

Samiadi. 2016. Alkohol dan Rokok Menyebabkan Hipertensi : Artikel (online) Available From : (https://hellosehat.com/benh/tekanandarah-tinggi-hipertensi/apakah-alkoholdan-rokok-menyebabkan-hipertensi/) diakses Maret 2019

Setiadi (2013). Konsep dan Praktek Penulisan Riset Keperawatan (Edisi 2). Yogyakarta: Graha Ilmu

Setyanda Gita, dkk. (2015). Hubungan Merokok dengan Kejadian Hipertensi pada Laki-Laki Usia 35-65 Tahun di Kota Padang. Padang: Jurnal FK Unand.

Sriani, I. K. (2017). Hubungan Antara Perilaku Merokok Dan Kebiasaan Olahraga Dengan Hipertensi Pada LakiLaki Usia 18-44 Tahun. Program Studi Kesehatan Masyarakat, Fakultas Kedokteran, Universitas Lambung Mangkurat.

Sudarmoko. (2015). Cara Menanggulangi Penyakit Hipertensi. Yogyakarta :Atma Madia Press.

Sukmana, Teddie. (2009). Mengenal Rokok dan Bahayanya. [Ebook].[dikutip pada 7 Juni 2016].

Sukmana T. (2008). Agar Terhindar Dari Rokok. Jakarta: Be Champion. Nuha Medika.

World Health Organization (2012). Prevalence Of Tabacco. 
e-Journal Keperawatan (e-Kp) Volume 7 Nomor 1, Mei 2019

World Health Organization (2008). Report On The Global Tobacco Epidemic.

Yashinta Octavian Gita Setyanda, D. S. (2015). Hubungan Merokok dengan Kejadian Hipertensi pada Laki-Laki Usia 35-65 Tahun di Kota Padang. Jurnal Kesehatan Andalas. 2015; 4(2) . 